\title{
Association Between Metabolic Syndrome and Periodontal Disease Measures in Postmenopausal Women: The Buffalo OsteoPerio Study
}

Michael J. LaMonte, * AnnaLynn M. Williams, ${ }^{*}$ Robert J. Genco, ${ }^{\dagger}$ Christopher A. Andrews, ${ }^{\ddagger}$ Kathy M. Hovey, * Amy E. Millen, * Richard W. Browne,§ Maurizio Trevisan,\| and Jean Wactawski-Wende*ף

Background: The objective of this study is to characterize the association between metabolic syndrome (MetS) and periodontitis in women, for which there is limited evidence.

Methods: Cross-sectional associations between MetS and periodontitis were examined in 657 postmenopausal women aged 50 to 79 years enrolled in a periodontal disease study ancillary to the Women's Health Initiative Observational Study. Whole-mouth measures of alveolar crest height (ACH), clinical attachment level (CAL), probing depth (PD), gingival bleeding, and supragingival plaque and measures to define MetS using National Cholesterol Education Program criteria were from a clinical examination. Study outcomes were defined as: 1) mean $A C H \geq 3 \mathrm{~mm}$, two sites $\geq 5 \mathrm{~mm}$, or tooth loss to periodontitis; 2) $\geq 2$ sites with CAL $\geq 6 \mathrm{~mm}$ and $\geq 1$ site with PD $\geq 5 \mathrm{~mm}$; 3) gingival bleeding at $\geq 50 \%$ of sites; and 4) supragingival plaque at $\geq 50 \%$ of sites. Logistic regression was used to estimate odds ratios (ORs) and 95\% confidence intervals (Cls).

Results: In unadjusted analyses, MetS (prevalence: 25.6\%) was significantly associated with supragingival plaque ( $\mathrm{OR}=1.74 ; 95 \% \mathrm{Cl}: 1.22$ to 2.50 ) and non-significantly associated with periodontitis defined by $\mathrm{ACH}(\mathrm{OR}=1.23 ; 95 \% \mathrm{CI}$ : 0.81 to 1.85$)$ and gingival bleeding (OR $=1.20 ; 95 \% \mathrm{CI}: 0.81$ to 1.77). Adjustment for age, smoking, and other confounders attenuated observed associations, though supragingival plaque remained significant $(\mathrm{OR}=1.47 ; 95 \% \mathrm{CI}: 1.00$ to $2.16 ; P=0.049)$. MetS was not associated with periodontitis defined by CAL and PD.

Conclusions: A consistent association between MetS and measures of periodontitis was not seen in this cohort of postmenopausal women. An association between MetS and supragingival plaque requires further investigation. J Periodontol 2014;85:1489-1501.

\section{KEY WORDS}

Diabetes mellitus; gingivitis; metabolic syndrome X; obesity; periodontitis; postmenopause.

\footnotetext{
* Department of Epidemiology and Environmental Health, School of Public Health and Health Professions, University at Buffalo, State University of New York, Buffalo, NY.

$\dagger$ Department of Oral Biology, School of Dental Medicine, University at Buffalo, State University of New York.

Department of Ophthalmology and Visual Sciences, University of Michigan Medical School, Ann Arbor, MI.

$\S$ Department of Biotechnical and Clinical Laboratory Sciences, School of Medicine and Biomedical Sciences, University at Buffalo, State University of New York.

|| Department of Community Health and Social Medicine, School of Biomedical Education, The City College of New York, New York, NY.

If Department of Gynecology-Obstetrics, School of Medicine and Biomedical Sciences, University at Buffalo, State University of New York.
} 
$\mathrm{P}$ eriodontal disease is a common, preventable disease with increasing public health implications among older adults. ${ }^{1,2}$ Recent findings indicate that $64 \%$ of U.S. adults 65 years and older have moderate to severe periodontal disease. ${ }^{3}$ Periodontal disease is associated with impaired dietary intake $\mathrm{e}^{4}$ and quality of life ${ }^{5}$ and higher risk of diabetes ${ }^{6}$ and cardiovascular mortality ${ }^{7}$ in older adults. Established periodontal risk factors include smoking, poorly controlled diabetes, and poor oral hygiene. ${ }^{8}$ Identifying other modifiable risk factors is a priority to improve population control of periodontal disease and its clinical complications. ${ }^{1,2,8}$

Metabolic syndrome (MetS) is a condition of coexisting factors including elevated blood pressure, dyslipidemia, hyperglycemia, and obesity that more than doubles the relative risks of diabetes and atherothrombosis. ${ }^{9,10}$ MetS afflicts 55\% of U.S. women 60 years and older ${ }^{11}$ likely owing to estrogen deficiencyinduced abdominal fat accretion and hepatic lipase upregulation common with menopause. ${ }^{12}$ MetS is a putative factor for modified host immune response and acceleration of periodontitis. ${ }^{13}$ Studies suggest that MetS could be adversely associated with periodontal disease. ${ }^{14-24}$ No study has focused on older postmenopausal women, who may be particularly susceptible to both conditions. The aim of the present study is to examine cross-sectional associations between MetS and several measures of periodontal disease in a well-characterized cohort of communitydwelling postmenopausal women.

\section{MATERIALS AND METHODS}

\section{Study Participants}

Participants were enrolled in the Buffalo Osteoporosis and Periodontal Disease (OsteoPerio) Study, ${ }^{25-27}$ a prospective cohort study on osteoporosis and periodontal disease ancillary to the Women's Health Initiative Observational Study (WHI-OS). ${ }^{28}$ Participants were recruited from 2,249 women aged 50 to 79 years enrolled in the parent WHI-OS during 1993 to 1998 at the Buffalo, New York, clinical center. Baseline assessments in the OsteoPerio study were conducted during 1997 to 2001 and formed the basis for the present study. Eligibility for the OsteoPerio study included: 1) at least six teeth; 2) no bilateral hip replacement; 3) no history of bone disease other than osteoporosis; and 4) no history of cancer in the past 10 years. Of the 1,341 women who completed baseline periodontal assessments, a venous blood sample was available in a subset of 657 women (aged $65.5 \pm 6.6$ years). Blood samples were available only in a subset of the study cohort because blood collection was not implemented until about a third of participants had completed study visits. Women with and without blood samples were compared, and there do not appear to be systematic differences in key demographic or clinical factors. Written consent was provided for all aspects of the WHI-OS and OsteoPerio studies, which were approved by the University at Buffalo Institutional Review Board.

\section{Oral Examinations}

Calibrated dental examiners performed whole-mouth oral examinations using procedures guided by national standards ${ }^{29}$ as previously described. ${ }^{25-27}$ The sequence of the periodontal measures was the same for all participants; the vast majority (>90\%) were completed during morning hours. Clinical probing methods were used to assess probing depth (PD), clinical attachment level (CAL), and gingival bleeding. PD was defined as the distance in millimeters from the gingival margin to the base of the gingival sulcus measured using a constant-force electronic probe $^{30}$ on six sites per tooth in all teeth except for third molars. Among a subset of 724 women in the OsteoPerio study, within-examiner coefficient of variation and intraclass correlation were $6 \%$ and 0.91 for replicate measures. A manual probe was used to measure the distance from the cemento-enamel junction (CEJ) to the gingival margin at the same six sites per tooth, and CAL was calculated by subtracting this distance from PD. Values for interproximal surfaces were used to calculate worst-site and composite whole-mouth mean PD and CAL. Extent and severity were also calculated for CAL and PD, ${ }^{25}$ with extent defined as the percent of interproximal sites reaching $\geq 4 \mathrm{~mm}$ and severity defined as the mean value across those sites. Gingival bleeding on swiping (absent or present) was assessed at three sites per tooth using the manual probe inserted $2 \mathrm{~mm}$ into the gingival sulcus parallel to the long axis of tooth, moving in a horizontal direction, and defined as the percentage of sites bleeding in the whole mouth. Supragingival plaque (absent or present) was assessed by inspection at the same three sites per tooth and defined as the percentage of sites with explorer-detectable supragingival plaque, regardless of amount.

Alveolar crest height $(\mathrm{ACH})$ was measured in seven anterior periapical and four posterior vertical bitewing radiographs using a single radiographic unit and cephalometric head positioner according to procedures developed by Hausmann et al. ${ }^{31}$ to enhance accuracy and resolution of $\mathrm{ACH}$ measures. ${ }^{25-27}$ Measurements were conducted on all teeth except third molars and canines, with two sites measured per tooth. Using the digitized images, $\mathrm{ACH}$ was measured as the distance in millimeters from the CEJ to the most coronal part of the alveolar crest in a plane parallel to the long axis of the tooth. In a subset of 885 women in the OsteoPerio study, the 
within-examiner coefficient of variation and intraclass correlation were $5.1 \%$ and 0.98 for replicate measures. Values for interproximal surfaces were used to calculate worst-site and composite wholemouth mean $\mathrm{ACH}$. Extent and severity as described above were also calculated for $\mathrm{ACH}$.

Periodontal disease status was characterized using two definitions. The first definition was derived from the OsteoPerio study ${ }^{27}$ and was based on $\mathrm{ACH}$ and tooth loss as follows: none (whole-mouth mean ACH $<2 \mathrm{~mm}$; no site $\geq 4 \mathrm{~mm}$; no reported tooth loss due to periodontal disease); mild/moderate (whole-mouth mean $\mathrm{ACH} \geq 2$ to $<3 \mathrm{~mm}$ or $\geq 1$ site $\geq 4 \mathrm{~mm}$ but no reported tooth loss due to periodontal disease); and severe (whole-mouth mean $\mathrm{ACH} \geq 3 \mathrm{~mm}$ or $\geq 2$ sites $\geq 5 \mathrm{~mm}$ or $\geq 1$ tooth loss due to periodontal disease). Second, the Centers for Disease Control and Prevention/ American Academy of Periodontology (CDC/AAP) definition ${ }^{32}$ based on CAL and PD was used as follows: none/mild (neither moderate nor severe periodontal disease); moderate ( $\geq 2$ interproximal sites with CAL $\geq 4 \mathrm{~mm}$ [not on same tooth] or $\geq 2$ interproximal sites with PD $\geq 5 \mathrm{~mm}$ [not on same tooth]); and severe ( $\geq 2$ interproximal sites with CAL $\geq 6 \mathrm{~mm}$ [not on same tooth] and $\geq 1$ interproximal site with PD $\geq 5 \mathrm{~mm}$ ).

\section{Blood Measures}

After overnight fasting and recommended abstinence from smoking and heavy exertion, venous blood samples were obtained, processed, portioned to serum and plasma, and frozen at $-80^{\circ} \mathrm{C}$. The samples assayed for this study had no previous thaw/freeze. Serum concentrations of glucose and triglyceride were measured using an enzymatic endpoint colorimetric assay, ${ }^{\#}$ and serum high-density lipoprotein cholesterol (HDL-C) was measured using a polyanion-polymer complex assay. ${ }^{*}$ Serum insulin and high-sensitivity $\mathrm{C}$-reactive protein (CRP) were measured using an electrochemiluminescence immunoassay $^{\dagger \dagger}$ and an immunoturbidimetric assay. ${ }^{\ddagger}$ Insulin and CRP were not measured in 37 samples due to sample volume requirements; thus these two measures were available in 620 participants (94\%). CRP $\geq 3 \mathrm{mg} / \mathrm{dL}$ was used to define the presence of systemic inflammation. ${ }^{33}$ Intra-assay coefficients of variation were $2.16 \%, 1.57 \%, 2.16 \%, 1.53 \%$, and $1.45 \%$ for glucose, triglyceride, HDL-C, insulin, and CRP, respectively.

\section{Other Assessments}

Body mass index (BMI, $\mathrm{kg} / \mathrm{m}^{2}$ ) was computed from height and weight measured using a clinical stadiometer and scale. Waist circumference was measured at the narrowest part of the torso using an anthropometric tape. After 5 minutes of quiet sitting, resting systolic and diastolic blood pressure (BP) was measured using auscultatory methods and an appropriately sized cuff based on measured arm circumference. The average of two measurements was recorded for analysis. Questionnaires were used to obtain information on demographic factors, personal medical history and medication use, oral hygiene and dental procedures, cigarette smoking, physical activity, and dietary intake. Reliability of clinical measures and self-reported medical and lifestyle information has been demonstrated among women enrolled in the WHI-OS. ${ }^{28}$

\section{MetS Definition}

MetS was defined using criteria of the National Cholesterol Education Program, ${ }^{9}$ requiring the presence of $\geq 3$ of the following: 1) abdominal obesity (waist circumference $>88 \mathrm{~cm}$ ); 2) elevated resting $\mathrm{BP}$ (systolic BP $\geq 135 \mathrm{mmHg}$ or diastolic BP $\geq 85 \mathrm{mmHg}$ or use of BP medication); 3) hypertriglyceridemia ( $\geq 150 \mathrm{mg} / \mathrm{dL}) ; 4$ ) hyperglycemia ( $\geq 100 \mathrm{mg} / \mathrm{dL}$ or use of diabetes medication); and 5) low HDL-C $(<50 \mathrm{mg} / \mathrm{dL}$ ). Waist circumference was missing in six participants, so BMI $\geq 30 \mathrm{~kg} / \mathrm{m}^{2}$ was used to define presence or absence of abdominal obesity in these individuals. In the cohort, the correlation between waist circumference and BMI was strong on a continuous scale (Spearman $r=0.86$ ) and when crossclassified according to categories of abdominal (waist $>88 \mathrm{~cm})$ and overall $(\mathrm{BMI} \geq 30)$ obesity $(\kappa=$ 0.59 ). Although hyperglycemia is one criterion for MetS, about half of adults with MetS do not have frank insulin resistance. ${ }^{34,35}$ Therefore, insulin resistance was also assessed using the homeostasis model assessment (HOMA) calculated as the product of fasting insulin $(\mu \mathrm{U} / \mathrm{L})$ and glucose $(\mathrm{mmol} / \mathrm{L})$, divided by $22.5 .^{36}$ Insulin resistance was categorically defined as HOMA $\geq 75$ th percentile ( $\geq 2.43$ units) in women without diagnosed diabetes ${ }^{35}$ and reported descriptively to further characterize the cohort.

\section{Statistical Analyses}

Demographic, health, and lifestyle characteristics and metabolic and periodontal parameters were compared between those with and without MetS using $\chi^{2}$ tests for proportions and independent $t$ tests or Wilcoxon rank sum tests of mean differences for continuous variables. MetS prevalence was examined across quartiles of PD, CAL, ACH, gingival bleeding, and plaque using Cochran-Armitage tests of linear trend. Binary logistic regression was used to further examine associations between MetS and periodontal disease measures. Because available studies have shown MetS to be associated with more severe ${ }^{16,18,19,22,23}$ rather than moderate ${ }^{14,15}$

\footnotetext{
\# Beckman LX20, Beckman, Brea, CA.

* Beckman LX20, Beckman.

$\dagger \dagger$ Roche Modular system, Roche Diagnostics, Mannheim, Germany.

牛 Roche Modular system, Roche Diagnostics.
} 
periodontitis, the periodontal outcome variables for these analyses were defined as severe periodontitis, as follows: clinically severe periodontitis defined by OsteoPerio (ACH-based) or CDC/AAP (PD- and CALbased) criteria described earlier; presence of gingival bleeding at $\geq 50 \%$ of sites measured; and presence of supragingival plaque at $\geq 50 \%$ of sites measured. Because of a small amount of missing data on periodontal probing measures, sample sizes varied slightly for analyses using CAL, gingival bleeding, and plaque (four missing, $\mathrm{n}=653$ each) compared with $\mathrm{ACH}$ (none missing, $\mathrm{n}=657$ ). Odds ratios (ORs), 95\% confidence intervals (Cls), and two-sided $P$ values were estimated to measure the strength, precision, and statistical significance $(\alpha=0.05)$ of these associations. Unadjusted, age- and smoking-adjusted, and multivariable-adjusted associations were estimated. Factors included in multivariable analyses were based on univariate relationships $(P \leq 0.05)$ with both MetS and periodontal disease status by OsteoPerio or CDC/AAP criteria.

\section{RESULTS}

MetS prevalence was $25.6 \%(n=168)$ among study participants. Prevalence of MetS components was $30.1 \%$ abdominal obesity, $12.3 \%$ hyperglycemia, 36.9\% hypertriglyceridemia, $45.8 \%$ elevated BP, and $37.7 \%$ low HDL-C. Women with MetS were, on average, older, less physically active, and had a higher percentage of total caloric intake from fat and lower percentage from carbohydrate compared with women without MetS $(P<0.05$ each) (Table 1$)$. The frequency of reported diagnosis of heart disease and diabetes was higher, and the frequency of current hormone therapy use was lower in women with than without MetS ( $P<0.05$ each). Women with MetS had higher metabolic risk factor values and higher prevalence of insulin resistance (HOMA $\geq 2.43$ units) and systemic inflammation ( $C R P \geq 3 \mathrm{mg} / \mathrm{dL}$ ) compared to women without MetS $(P<0.01$ each).

Whole-mouth mean and worst-site $\mathrm{ACH}, \mathrm{PD}$, and CAL were not significantly different between women with and without MetS (Table 2). Likewise, when using a $\geq 4$-mm threshold, extent and severity of $\mathrm{ACH}, \mathrm{PD}$, and CAL did not differ between groups. Women with MetS did, however, have a significantly greater mean number of sites with gingival bleeding $(P=0.01)$ and supragingival plaque $(P=0.004)$, and a higher proportion of these women had supragingival plaque at $\geq 50 \%$ of sites measured $(P=$ $0.002)$ compared with women without MetS. The mean number of teeth present and the frequency of reported toothbrushing and dental visits also were significantly lower in those with than without MetS $(P<0.05$ each). Classification into periodontal disease categories using OsteoPerio or CDC/AAP criteria was not different according to MetS status. As seen in Table 3, MetS prevalence did not differ across quartiles of worst-site or whole-mouth mean $\mathrm{ACH}, \mathrm{CAL}$, or PD but was significantly higher across incremental quartiles of gingival bleeding (trend: $P=$ 0.02 ) and supragingival plaque (trend: $P=0.008$ ).

Next, logistic regression analysis was used to examine associations between MetS presence and measures of severe periodontitis (Table 4). In unadjusted analyses, MetS was significantly associated with supragingival plaque (OR $=1.74 ; 95 \% \mathrm{CI}: 1.22$ to 2.50 ; $P=0.002)$ and non-significantly associated with ACH $(\mathrm{OR}=1.23 ; 95 \% \mathrm{CI}: 0.81,1.85 ; P=0.34)$ and gingival bleeding ( $\mathrm{OR}=1.20 ; 95 \% \mathrm{CI}$ : 0.81 to 1.77 ; $P=0.36)$. Adjustment for age and smoking attenuated these associations; however, supragingival plaque remained significantly associated with MetS $(\mathrm{OR}=1.63 ; 95 \% \mathrm{CI}: 1.13$ to $2.35 ; P=0.008)$. Additional adjustment for hormone therapy use, history of diagnosed heart disease, toothbrushing and dental visits, physical activity, and percent caloric intake from fat further attenuated associations, though supragingival plaque remained statistically significant $(\mathrm{OR}=1.47 ; 95 \% \mathrm{CI}: 1.00$ to $2.16 ; P=0.049)$. Because the presence of gingival plaque could coexist with heightened inflammation as part of an altered host response to gingival insult, ${ }^{13,37}$ an exploratory analysis was conducted stratifying the association according to serum CRP values of $<3$ and $\geq 3 \mathrm{mg} / \mathrm{dL}$ and inspecting for changes in the magnitude of point and interval estimates to guide interpretation of this analysis. The multivariable association between MetS and supragingival plaque was strengthened in women with high serum CRP $(\mathrm{n}=240 ; 79$ MetS cases, 52 plaque cases; $\mathrm{OR}=2.04$; 95\% CI: 1.12 to 3.74; $P=0.02)$ and attenuated in those with lower CRP $(n=380 ; 78$ MetS cases, 42 plaque cases; $\mathrm{OR}=1.07 ; 95 \% \mathrm{CI}: 0.62$ to 1.84 ; $P=0.82)$.

The authors also examined associations between each MetS component and the periodontal measures (Table 5). Abdominal obesity tended to carry associations of moderate strength (ORs of 1.24 to 1.54), whereas associations for other components were variable. The strongest associations tended to be with supragingival plaque.

Sensitivity analyses were conducted to explore the role that diagnosed diabetes and oral hygiene may have in the observed associations. After excluding women with diagnosed treated diabetes mellitus ( $n=24)$, multivariable results (data not shown) were materially the same as those shown in Table 4, suggesting that existing diabetes had little impact on the observed associations, likely due to its relatively low prevalence in the cohort. Multivariable analyses including all covariables except 
Table I.

\section{Participant Characteristics for All Women and According to MetS Status}

\begin{tabular}{|c|c|c|c|c|}
\hline \multirow[b]{2}{*}{ Characteristic } & \multirow[b]{2}{*}{ All Women } & \multicolumn{2}{|c|}{ MetS } & \multirow[b]{2}{*}{$P$} \\
\hline & & Absent & Present & \\
\hline $\begin{array}{l}\text { Age at visit (years) } \\
<60 \\
\quad 60 \text { to } 69 \\
\geq 70\end{array}$ & $\begin{array}{l}65.5 \pm 6.6 \\
147(22.3) \\
321(48.8) \\
189(28.7)\end{array}$ & $\begin{array}{l}65.1 \pm 6.6 \\
120(24.5) \\
235(48.0) \\
134(27.4)\end{array}$ & $\begin{array}{l}66.6 \pm 6.7 \\
27(16.0) \\
86(51.1) \\
55(32.7)\end{array}$ & $\begin{array}{l}0.02 \\
0.06\end{array}$ \\
\hline White & $649(98.7)$ & $483(98.7)$ & $166(98.9)$ & 0.97 \\
\hline College education or graduate school & $5 \mid 8(80.0)$ & $389(80.7)$ & $129(78.1)$ & 0.18 \\
\hline $\begin{array}{l}\text { Cigarette smoking } \\
\text { Never } \\
\text { Former } \\
\text { Current }\end{array}$ & $\begin{array}{c}360(54.7) \\
283(43.0) \\
14(2.1)\end{array}$ & $\begin{array}{c}269(55.0) \\
211(43.1) \\
\quad 9(1.8)\end{array}$ & $\begin{array}{c}91(54.1) \\
72(42.8) \\
5(2.9)\end{array}$ & 0.68 \\
\hline History of diagnosed heart disease & $56(8.5)$ & $35(7.1)$ & $21(12.5)$ & 0.03 \\
\hline History of diagnosed diabetes & $24(3.6)$ & $6(1.2)$ & $18(10.7)$ & $<0.00$ । \\
\hline History of diagnosed hypertension & $216(32.9)$ & $115(23.5)$ & $101(60.1)$ & $<0.00$ I \\
\hline Age at menopause (years) & $48.1 \pm 5.3$ & $48.1 \pm 5.0$ & $47.8 \pm 6.4$ & 0.58 \\
\hline Recreational physical activity (MET-hours/week) & $14.5 \pm 14.6$ & $|6| \pm.|5|$. & $9.8 \pm 11.8$ & $<0.00$ । \\
\hline Waist circumference $(\mathrm{cm})$ & $83.9 \pm 11.9$ & $80.4 \pm 9.6$ & $94.1 \pm 12.1$ & $<0.00$ । \\
\hline Glucose (mg/dL), median (IQR) & $85.0(13.0)$ & $84.0(11.0)$ & $94.0(27.5)$ & $<0.001$ \\
\hline Triglyceride (mg/dL), median (IQR) & $127.0(89.0)$ & $109.0(60.0)$ & $199.5(92.0)$ & $<0.001$ \\
\hline HDL cholesterol (mg/dL) & $54.6 \pm 15.0$ & $58.6 \pm 14.5$ & $43.1 \pm 9.4$ & $<0.001$ \\
\hline Systolic BP (mmHg) & $121.4 \pm 18.0$ & $118.6 \pm 17.2$ & $129.7 \pm 17.8$ & $<0.001$ \\
\hline Diastolic BP (mmHg) & $70.9 \pm 8.8$ & $70.3 \pm 8.7$ & $72.6 \pm 9.1$ & 0.005 \\
\hline Insulin ( $\mu \cup / L)$, median (IQR) & $6.4(7.2)$ & $5.5(4.1)$ & $13.3(12.1)$ & $<0.001$ \\
\hline HOMA (units), median (IQR)* & $1.3(1.6)$ & I.I (0.9) & $3.1(3.5)$ & $<0.00$ । \\
\hline Insulin resistance ${ }^{\dagger}$ & $168(27.0)$ & $69(14.9)$ & $99(63.0)$ & $<0.00$ । \\
\hline CRP (mg/L), median (IQR)* & $2.2(3.2)$ & $1.9(3.1)$ & $3.0(3.5)$ & $<0.001$ \\
\hline High CRP ( $\geq 3 \mathrm{mg} / \mathrm{dL})$ & $240(38.7)$ & $162(34.9)$ & $79(50.3)$ & $<0.00$ । \\
\hline
\end{tabular}

$\mathrm{IQR}=$ interquartile range; $\mathrm{MET}=$ metabolic equivalent of task.

Data given as mean \pm SD or $\mathrm{n}(\%)$ unless otherwise noted.

* Total $\mathrm{n}=620$.

$\dagger$ Defined as HOMA value $\geq 75$ th percentile ( $\geq 2.43$ units) among women without diabetes. 
Table 2.

\section{Periodontal Measures for all Women and According to MetS Status}

\begin{tabular}{|c|c|c|c|c|}
\hline \multirow[b]{2}{*}{ Characteristic } & \multirow[b]{2}{*}{ All Women } & \multicolumn{2}{|c|}{ MetS } & \multirow[b]{2}{*}{$P$} \\
\hline & & Absent & Present & \\
\hline $\mathrm{n}$ & 657 & $489(74.4)$ & $168(25.6)$ & \\
\hline \multicolumn{5}{|l|}{$\mathrm{ACH}(\mathrm{mm})$} \\
\hline Worst-site & & & & 0.29 \\
\hline Mean \pm SD & $4.4 \pm 1.5$ & $4.4 \pm 1.4$ & $4.6 \pm 1.7$ & \\
\hline Range & 2.0 to 12.6 & 2.0 to 11.5 & 2.0 to 12.6 & \\
\hline Whole-mouth mean & & & & 0.40 \\
\hline Mean \pm SD & $2.3 \pm 0.7$ & $2.3 \pm 0.6$ & $2.4 \pm 0.8$ & \\
\hline Range & 1.0 to 8.9 & 1.0 to 6.4 & 1.2 to 8.9 & \\
\hline \multicolumn{5}{|c|}{ Whole-mouth mean $\geq 4 \mathrm{~mm}$ at $\geq 1$ site } \\
\hline Extent (\%)* & & & & 0.53 \\
\hline Mean \pm SD & $7.3 \pm 13.3$ & $7.1 \pm 13.0$ & $7.8 \pm 14.0$ & \\
\hline Range & 0 to 100 & 0 to 100 & 0 to 100 & \\
\hline Severity $(\mathrm{mm})^{\dagger}$ & & & & 0.65 \\
\hline Mean \pm SD & $4.7 \pm 0.6$ & $4.7 \pm 0.5$ & $4.7 \pm 0.7$ & \\
\hline Range & 4.0 to 8.9 & 4.0 to 7.1 & 4.0 to 8.9 & \\
\hline \multicolumn{5}{|l|}{ CAL (mm) } \\
\hline Worst-site & & & & 0.29 \\
\hline Mean \pm SD & $5.7 \pm 1.7$ & $5.6 \pm 1.6$ & $5.8 \pm 1.8$ & \\
\hline Range & 2.8 to 13.8 & 2.8 to 13.8 & 3.0 to 12.6 & \\
\hline Whole-mouth mean & & & & 0.57 \\
\hline Mean \pm SD & $2.4 \pm 0.6$ & $2.4 \pm 0.6$ & $2.4 \pm 0.6$ & \\
\hline Range & I.I to 7.3 & 1.2 to 5.1 & 1.1 to 7.3 & \\
\hline \multicolumn{5}{|c|}{ Whole-mouth mean $\geq 4 \mathrm{~mm}$ at $\geq 1$ site } \\
\hline Extent (\%)* & & & & 0.26 \\
\hline Mean \pm SD & $10.6 \pm 13.2$ & $10.3 \pm 12.9$ & $11.6 \pm 14.0$ & \\
\hline Range & 0 to 100 & 0 to 81.8 & 0 to 100 & \\
\hline Severity $(\mathrm{mm})^{\dagger}$ & & & & 0.17 \\
\hline Mean \pm SD & $4.7 \pm 0.5$ & $4.7 \pm 0.5$ & $4.7 \pm 0.5$ & \\
\hline Range & 4.0 to 9.3 & 4.0 to 7.3 & 4.0 to 9.3 & \\
\hline \multicolumn{5}{|l|}{$\mathrm{PD}(\mathrm{mm})$} \\
\hline Worst-site & & & & 0.72 \\
\hline Mean \pm SD & $4.9 \pm 1.2$ & $4.8 \pm 1.2$ & $4.9 \pm 1.3$ & \\
\hline Range & 2.4 to 10.8 & 2.4 to 10.8 & 2.8 to 9.8 & \\
\hline Whole-mouth mean & & & & 0.94 \\
\hline Mean $\pm S D$ & $2.2 \pm 0.3$ & $2.2 \pm 0.3$ & $2.2 \pm 0.4$ & \\
\hline Range & 1.4 to 4.0 & 1.4 to 4.0 & 1.5 to 3.7 & \\
\hline \multicolumn{5}{|c|}{ Whole-mouth mean $\geq 4 \mathrm{~mm}$ at $\geq 1$ site } \\
\hline Extent (\%)* & & & & 0.32 \\
\hline Mean \pm SD & $4.9 \pm 6.4$ & $4.8 \pm 6.2$ & $5.4 \pm 6.9$ & \\
\hline Range & 0 to 49.0 & 0 to 49.0 & 0 to 35.7 & \\
\hline Severity $(\mathrm{mm})^{\dagger}$ & & & & 0.40 \\
\hline Mean \pm SD & $4.5 \pm 0.4$ & $4.5 \pm 0.4$ & $4.5 \pm 0.4$ & \\
\hline Range & 4.0 to 7.2 & 4.0 to 7.2 & 4.0 to 7.0 & \\
\hline Gingival bleeding, $\mathrm{n}$ sites & $0.3 \pm 0.2$ & $0.3 \pm 0.2$ & $0.4 \pm 0.2$ & 0.01 \\
\hline$\geq 50 \%$ of sites & $175(26.8)$ & $126(25.8)$ & 49 (29.5) & 0.36 \\
\hline $\mathrm{Pl}, \mathrm{n}$ sites & $0.5 \pm 0.2$ & $0.1 \pm 0.2$ & $0.5 \pm 0.2$ & 0.004 \\
\hline$\geq 50 \%$ of sites & $335(51.2)$ & $233(47.7)$ & $102(61.2)$ & 0.002 \\
\hline
\end{tabular}


Table 2. (continued)

\section{Periodontal Measures for all Women and According to MetS Status}

\begin{tabular}{|c|c|c|c|c|}
\hline \multirow[b]{2}{*}{ Characteristic } & \multirow[b]{2}{*}{ All Women } & \multicolumn{2}{|c|}{ MetS } & \multirow[b]{2}{*}{$P$} \\
\hline & & Absent & Present & \\
\hline Teeth present, $n$ & $23.8 \pm 4.8$ & $24.2 \pm 4.4$ & $22.6 \pm 5.7$ & 0.001 \\
\hline Tooth loss to periodontitis, $n$ & $0.4 \pm 2.2$ & $0.4 \pm 2.2$ & $0.3 \pm 1.9$ & 0.65 \\
\hline Toothbrushing $\geq 2$ times per day & $503(76.5)$ & $387(79.1)$ & $116(69.0)$ & 0.007 \\
\hline Floss teeth daily & $281(42.8)$ & $213(43.6)$ & $68(40.4)$ & 0.72 \\
\hline Dental visit $\geq \mid$ time per year & 607 (92.4) & $458(93.6)$ & $149(88.6)$ & 0.047 \\
\hline \multicolumn{5}{|l|}{ Periodontal disease status } \\
\hline OsteoPerio definition ${ }^{27}$ & & & & 0.55 \\
\hline None & $180(27.4)$ & $133(27.2)$ & $47(27.9)$ & \\
\hline Mild/moderate & $334(50.8)$ & $254(51.9)$ & $80(47.6)$ & \\
\hline Severe & $143(21.7)$ & $102(20.8)$ & $41(24.4)$ & \\
\hline CDC/AAP definition ${ }^{32}$ & & & & 0.76 \\
\hline None/mild & $147(22.5)$ & $107(21.9)$ & $40(23.1)$ & \\
\hline Moderate & $401(61.0)$ & $303(62.2)$ & $98(59.0)$ & \\
\hline Severe & $105(16.0)$ & $77(15.8)$ & $28(16.8)$ & \\
\hline
\end{tabular}

Data given as mean \pm SD or $\mathrm{n}(\%)$.

* Percent of total sites with $\geq 4 \mathrm{~mm}$ in $\mathrm{ACH}, \mathrm{CAL}$, or PD

$\dagger$ Mean $\mathrm{ACH}, \mathrm{CAL}$, or PD at sites with $\geq 4 \mathrm{~mm}$.

for toothbrushing and dental visits (data not shown) were comparable to those in Tables 4 and 5, suggesting that controlling for oral hygiene did not overadjust the associations in the cohort.

\section{DISCUSSION}

Menopausal hormone changes give rise to metabolic abnormalities predisposing postmenopausal women to MetS and periodontitis. ${ }^{12,13}$ The present crosssectional study in ambulatory postmenopausal women indicates that MetS was significantly and positively associated with presence of supragingival plaque. The association persisted after adjustment for age, smoking, hormone therapy use, history of diagnosed heart disease, oral hygiene, and lifestyle habits and was somewhat stronger in women with elevated serum CRP, a marker of systemic inflammation. MetS tended to be positively associated with measures of severe periodontitis defined by $\mathrm{ACH}$ and gingival bleeding; however, these associations did not reach statistical significance and were substantially attenuated in multivariable analyses. With the exception of abdominal obesity, associations between MetS components and periodontitis were less consistent and generally not statistically significant. MetS was not associated with CAL and PD measures of periodontitis, including when using CDC/AAP criteria. To the authors' knowledge, this is the most comprehensive evaluation of MetS and periodontitis and the only study focused on older postmenopausal women. Study strengths include the well-characterized cohort of postmenopausal women, availability of several periodontal measures (including $\mathrm{ACH}$ from oral radiographs and gingival measures from probing procedures), availability of measured phenotypes to define MetS using standard clinical criteria, and availability of information on relevant covariables for consideration in multivariable analyses. Given the projected doubling of older U.S. adults in the coming decades ${ }^{38}$ and the associated burden of periodontal disease, ${ }^{1,3}$ an association with MetS could have implications for improved control of periodontal disease and shared clinical complications.

One other study has been published on the association between MetS and supragingival plaque. Li et al. ${ }^{20}$ examined 208 adults (mean age: 60 years [59\% women]), and after adjustment for age, sex, and smoking, showed that MetS was significantly associated with whole-mouth supragingival plaque index (PI). The present findings generally were in agreement with those of $\mathrm{Li}$ et al. A significant trend was observed for higher prevalence of MetS across incremental quartiles of supragingival plaque and, after adjustment for age and smoking, 67\% higher relative odds of having severe supragingival plaque were observed in women with MetS. After further adjustments, the multivariable odds of supragingival plaque remained $47 \%$ higher in women with MetS in the overall cohort and two-fold higher in the subset of women with evidence of systemic inflammation 
Table 3.

\section{Prevalence of MetS Across Quartiles of Periodontal Disease Measures}

\begin{tabular}{|c|c|c|c|c|c|}
\hline \multirow[b]{2}{*}{ Characteristic } & \multicolumn{4}{|c|}{ Periodontal Quartile } & \multirow[b]{2}{*}{$P$, trend* } \\
\hline & I (low) & 2 & 3 & 4 (high) & \\
\hline \multicolumn{6}{|l|}{ Worst-site ACH } \\
\hline Median (mm) & & 3.8 & 4.5 & 6.0 & \multirow{3}{*}{0.91} \\
\hline Metabolic syndrome, $\mathrm{n}$ & 42 & 43 & 39 & 44 & \\
\hline$\%(\mathrm{SE})$ & $25.4(3.3)$ & $26.2(3.4)$ & $23.7(3.3)$ & $26.8(3.4)$ & \\
\hline \multicolumn{6}{|l|}{ Whole-mouth mean $\mathrm{ACH}$} \\
\hline Median (mm) & 1.6 & 2.0 & 2.4 & 3.0 & \multirow{3}{*}{0.50} \\
\hline MetS, n & 42 & 36 & 46 & 44 & \\
\hline \% (SE) & $25.3(3.3)$ & $22.0(3.2)$ & $28.2(3.5)$ & $26.6(3.4)$ & \\
\hline \multirow{2}{*}{\multicolumn{5}{|c|}{ Worst-site CAL }} & \multirow{4}{*}{0.37} \\
\hline Median (mm) & & & & 7.6 & \\
\hline MetS, n & 44 & 31 & 42 & 49 & \\
\hline$\%(\mathrm{SE})$ & $24.8(3.2)$ & $21.9(3.4)$ & $26.0(3.4)$ & $28.1(3.4)$ & \\
\hline \multicolumn{5}{|l|}{ Whole-mouth mean CAL } & \multirow{4}{*}{0.37} \\
\hline Median (mm) & 1.8 & 2.1 & 2.4 & 3.0 & \\
\hline MetS, n & 41 & 40 & 35 & 50 & \\
\hline \% (SE) & $25.3(3.4)$ & $24.2(3.3)$ & $21.3(3.2)$ & $30.8(3.6)$ & \\
\hline \multicolumn{5}{|l|}{ Worst-site PD } & \multirow{4}{*}{0.93} \\
\hline Median (mm) & 3.6 & 4.4 & 5.0 & 6.2 & \\
\hline MetS, n & 34 & 52 & 42 & 39 & \\
\hline$\%(\mathrm{SE})$ & $22.8(3.4)$ & $27.3(3.2)$ & $30.0(3.8)$ & $22.2(3.1)$ & \\
\hline \multicolumn{5}{|l|}{ Whole-mouth mean PD } & \multirow{4}{*}{0.46} \\
\hline Median (mm) & 1.8 & 2.0 & 2.3 & 2.6 & \\
\hline MetS, n & 42 & 51 & 32 & 42 & \\
\hline$\%(\mathrm{SE})$ & $25.7(3.4)$ & $30.5(3.5)$ & $20.1(3.1)$ & $25.4(3.3)$ & \\
\hline \multicolumn{5}{|l|}{ Gingival bleeding } & \multirow{4}{*}{0.02} \\
\hline Median & 0.1 & 0.2 & 0.4 & 0.6 & \\
\hline MetS, n & 31 & 38 & 53 & 44 & \\
\hline \% (SE) & $18.9(3.0)$ & $23.6(3.3)$ & $31.3(3.5)$ & $27.6(3.5)$ & \\
\hline \multicolumn{5}{|l|}{ PI } & \multirow{4}{*}{0.008} \\
\hline Median & 0.2 & 0.4 & 0.6 & 0.8 & \\
\hline MetS, n & 32 & 34 & 52 & 48 & \\
\hline \% (SE) & $19.3(3.0)$ & $20.9(3.2)$ & $32.1(3.6)$ & $29.0(3.5)$ & \\
\hline
\end{tabular}

* Cochran-Armitage test.

by CRP. The proportion of women reporting toothbrushing at least twice a day and dental visits at least once a year was significantly lower in women with than without MetS. The lower frequency of toothbrushing could increase plaque in MetS, as could seeing a dentist less frequently. MetS is associated with chronic inflammation, ${ }^{9}$ and periodontitis is a chronic inflammatory disease ${ }^{13}$ emanating from gingival insult by polymicrobial dental plaque, ${ }^{37}$ which could account for a somewhat stronger association in women with evidence of systemic inflammation.

The association between MetS and $\mathrm{ACH}$ has been reported by one other study. Nesbitt et al. ${ }^{22}$ used whole-mouth radiographs to define severe periodontitis as $\mathrm{ACH} \geq 3 \mathrm{~mm}$ in 200 adults (mean age: 56 years, $42 \%$ women) and, after adjusting for age, sex, and smoking, showed an OR of $2.61 \quad(P<0.05)$ for severe periodontitis in those with MetS. Although in the present study MetS is associated with a nonsignificant $14 \%$ higher age- and smoking-adjusted relative odds of severe periodontitis defined by $\mathrm{ACH}$, mean values of whole-mouth and worst-site $\mathrm{ACH}$, and the extent and severity of $\mathrm{ACH}$ (4-mm threshold), did not differ by MetS status.

One other study has reported findings on the association between MetS and gingival bleeding. 
Table 4.

\section{ORs and 95\% CIs for Periodontal Disease According to MetS Status}

\begin{tabular}{|c|c|c|c|}
\hline \multirow[b]{2}{*}{ Periodontal Disease Outcome } & \multicolumn{2}{|c|}{ MetS } & \multirow[b]{2}{*}{$P$} \\
\hline & Absent & Present & \\
\hline $\begin{array}{l}\text { Severe periodontitis by } \mathrm{ACH} \text { (OsteoPerio definition }{ }^{27} \text { ) } \\
\text { Cases, } \mathrm{n}(\%) \\
\text { Unadjusted } \\
\text { Age- and smoking-adjusted } \\
\text { Multivariable-adjusted* }\end{array}$ & $\begin{array}{l}102(20.8) \\
1.00 \text { (referent) } \\
1.00 \text { (referent) } \\
1.00 \text { (referent) }\end{array}$ & $\begin{array}{l}41(24.4) \\
\text { I.23 }(0.8 \text { I to } 1.85) \\
\text { I.I4 }(0.74 \text { to } 1.74) \\
\text { I.II }(0.7 \mid \text { to } 1.75)\end{array}$ & $\begin{array}{l}0.34 \\
0.55 \\
0.64\end{array}$ \\
\hline $\begin{array}{l}\text { Severe periodontitis by CAL, PD (CDC-AAP definition }{ }^{32} \text { ) } \\
\text { Cases, } n(\%) \\
\text { Unadjusted } \\
\text { Age- and smoking-adjusted } \\
\text { Multivariable-adjusted* }\end{array}$ & $\begin{array}{l}77(15.8) \\
1.00 \text { (referent) } \\
1.00 \text { (referent) } \\
1.00 \text { (referent) }\end{array}$ & $\begin{array}{l}28(16.8) \\
1.08(0.67 \text { to } 1.74) \\
1.07(0.67 \text { to } 1.73) \\
1.02(0.62 \text { to } 1.68)\end{array}$ & $\begin{array}{l}0.75 \\
0.77 \\
0.93\end{array}$ \\
\hline $\begin{array}{l}\text { PI } \geq 50 \% \text { of sites } \\
\text { Cases, } n(\%) \\
\text { Unadjusted } \\
\text { Age- and smoking-adjusted } \\
\text { Multivariable-adjusted* }\end{array}$ & $\begin{array}{l}233 \text { (47.7) } \\
1.00 \text { (referent) } \\
1.00 \text { (referent) } \\
1.00 \text { (referent) }\end{array}$ & $\begin{array}{l}102(61.4) \\
1.74(1.22 \text { to } 2.50) \\
1.63(1.13 \text { to } 2.35) \\
1.47(1.00 \text { to } 2.16)\end{array}$ & $\begin{array}{l}0.002 \\
0.008 \\
0.049\end{array}$ \\
\hline
\end{tabular}

* Adjusted for age (years), smoking (never, ever), hormone therapy use (never, former, current), history of diagnosed heart disease (yes, no), toothbrushing ( $<2$ times/day, $\geq 2$ times/day), dental visits (never or only with problem, $\geq 1$ time/year), recreational physical activity (metabolic equivalent of task [MET]hours/week), and percent daily caloric intake from fat.

D'Aiuto et al. ${ }^{15}$ reported a multivariable-adjusted OR of $1.12(P<0.05)$ associated with each $10 \%$ increment in percentage bleeding sites among 13,677 adults ( $\geq 17$ years old, $51 \%$ women) in the U.S. National Health and Nutrition Examination Survey (1988 to 1994). Significantly more mean sites with bleeding were observed in women with MetS, and significantly higher MetS prevalence was observed across incremental quartiles of gingival bleeding. After adjusting for age and smoking, a non-significant $17 \%$ higher relative odds of severe gingival bleeding was associated with MetS, but further adjustment weakened this relationship.

Contrary to these results, several studies have shown statistically significant positive associations between MetS and measures of CAL and PD 16-21,23,24 including CDC/AAP criteria. ${ }^{15}$ Among older adults, multivariableadjusted ORs have been 1.74 for severe periodontitis by CDC/AAP criteria ${ }^{15}$ to as high as 6.0 for PD $\geq 4$ mm. ${ }^{18}$ Little difference was found in mean CAL and PD, extent and severity of CAL and PD (4-mm threshold), or CDC/AAP disease classification when comparing MetS groups, and prevalence of MetS did not differ according to quartiles of CAL or PD.
It is not clear why these findings for CAL and PD are inconsistent with those of other published studies. Potential explanations involve differences in case definitions or prevalence of MetS and periodontitis. As in this study, most published studies ${ }^{14-19,21-23}$ defined MetS using National Cholesterol Education PanelAdult Treatment Panel III criteria or slight modifications thereof. MetS prevalence has ranged from as low as $8 \%^{21}$ to as high as $28 \%,{ }^{14}$ with a majority of studies reporting $\approx 15 \% .{ }^{16,22-24}$ In the present study, MetS prevalence was $25 \%$, which is within the range reported in previous studies showing positive associations between MetS and periodontitis. ${ }^{16,19,22-24}$ Prevalence of MetS components also was comparable with previous studies on periodontal disease, ${ }^{14,19,23}$ including prevalence of hyperglycemia and abdominal obesity, which are known periodontal risk factors. ${ }^{6,39}$ Although MetS prevalence in the present study on older postmenopausal women is comparable to that in previous periodontal studies and in the WHI study, ${ }^{40,41}$ prevalence is curiously lower than expected in women of similar age nationally. ${ }^{11}$ Even so, insufficient MetS prevalence does not likely explain the lack of stronger findings in the present study. 


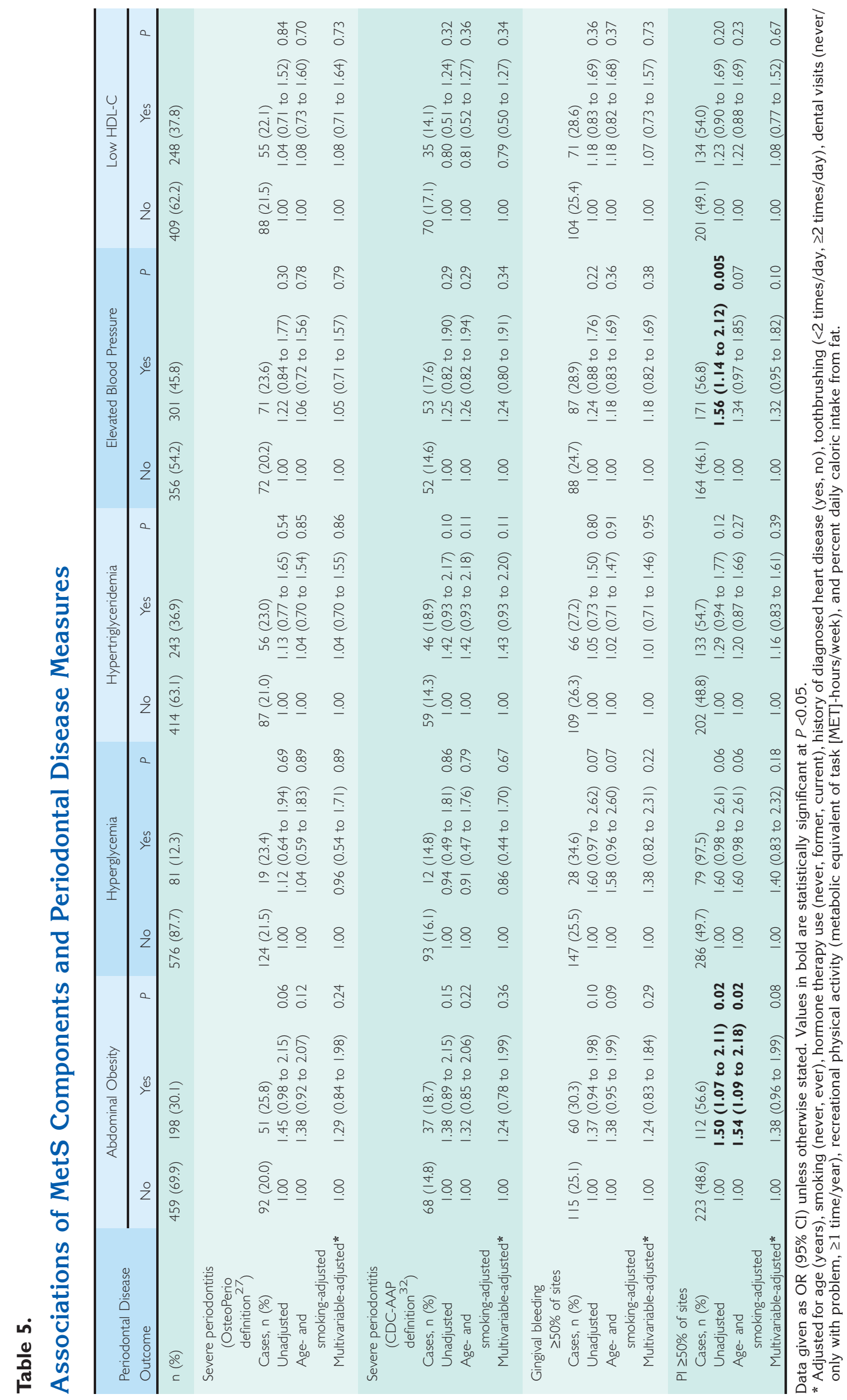


Availability of several periodontal measures allowed for examination of periodontitis case definitions of comparable severity and prevalence as reported in previous investigations on MetS. The threshold of $4 \mathrm{~mm}$ for defining extent and severity of CAL and PD is similar to thresholds used by others for CAL ${ }^{16,20,23}$ and PD, ${ }^{16-19,21,24}$ as is classification by CDC/AAP criteria. ${ }^{14,15}$ Likewise, the thresholds for ACH-defined periodontitis is comparable to the threshold and prevalence reported by Nesbitt et al. ${ }^{22}$ Periodontal measures were from wholemouth examinations as in most ${ }^{14,16,19,20,22,24}$ but not all ${ }^{15,18,21,23}$ previous studies. It is unlikely that differences in the nature of oral examinations or the severity or prevalence of periodontal disease explain the discordance between the present and previous study findings.

Smoking is a strong determinant of periodontal disease presence and severity ${ }^{3,8,27}$ and is correlated with MetS presence. ${ }^{11}$ Prevalence of current smoking was only $2 \%$ in the present cohort of older women, lower than reported in most studies on MetS and periodontitis. Significant positive associations between MetS and periodontitis have been reported in analyses restricted to non-smokers. ${ }^{15,20,21,24}$ Differences in prevalence of current smokers likely does not fully account for the disparate findings.

Not all published studies have shown an association between MetS and periodontitis, ${ }^{14}$ particularly when restricted to women. ${ }^{17,18,21}$ Benguigui et al. ${ }^{14}$ showed in 255 adults after adjustments for age, sex, and smoking that MetS was not significantly associated with periodontitis defined by CDC/AAP criteria. In that relatively small study, the criteria and prevalence of MetS and periodontitis were comparable to the present study. In three other studies, ${ }^{17,18,21}$ when analyses were restricted to women $(\mathrm{n} \approx 500)$, associations between MetS and periodontitis were attenuated and no longer significant. However, significant associations have been reported specifically in women. ${ }^{16,19}$

The reasons for inconsistent findings in women are unclear. The authors hypothesized that hormonal and metabolic changes with menopause contribute to both systemic and local inflammation as the basis for observing a relationship between MetS and measures of severe periodontitis in older postmenopausal women. Indeed, an association was observed with supragingival plaque and gingival bleeding, which are related to local inflammation. The association with plaque was strengthened in the presence of elevated CRP, a marker of systemic inflammation. Findings were less consistent with other periodontal measures. As speculated by others, ${ }^{19,20}$ MetS could be most influential on acute inflammatory stages of periodontal disease, such as plaque accretion and gingivitis, and less so in more chronic stages of disease such as alveolar bone loss. Although the present findings align somewhat with this supposition, the authors also would have expected stronger and more consistent relationships with PD. Factors known to be related with inflammation and periodontitis, such as hormone therapy use, diagnosed heart disease, and health behaviors, differed between women with and without MetS. Although statistical procedures were used to control for the influence of these variables, it is possible that residual effects remained. Limitations of the present study include the crosssectional design, which precludes causal inference. Statistical power to detect small associations may have been limited by sample size. The cohort is largely white and college educated; however, there are no published data showing that association between MetS and periodontitis differs according to race/ethnicity or education status. Although participants were required to have $\geq 6$ teeth for study enrollment and oral hygiene was quite good, the prevalence of severe periodontitis was similar to that in other studies on MetS. These study characteristics need be considered when generalizing these findings to other groups.

\section{CONCLUSIONS}

In conclusion, MetS was not consistently associated with periodontal measures in this cohort of ambulatory community-dwelling older postmenopausal women. Measures of gingival plaque and inflammation were associated overall and by abdominal obesity. Further investigation is required to clarify these findings.

\section{ACKNOWLEDGMENTS}

This study was supported by the following funding sources: National Heart, Lung, and Blood Institute contract N01WH32122; National Institute for Dental and Craniofacial Research Grants: DE13505, DE04898, and DE022654; and U.S. Army Reserve Medical Corps Grant: DAMD17-96-1-6319. The authors report no conflicts of interest related to this study.

\section{REFERENCES}

1. Griffin SO, Jones JA, Brunson D, Griffin PM, Bailey WD. Burden of oral disease among older adults and implications for public health priorities. Am J Public Health 2012;1023:411-418.

2. Petersen PE, Yamamoto T. Improving the oral health of older people: The approach of the WHO Global Oral Health Programme. Community Dent Oral Epidemiol 2005;33:81-92.

3. Eke PI, Dye BA, Wei L, Thornton-Evans GO, Genco RJ; CDC Periodontal Disease Surveillance workgroup. Prevalence of periodontitis in adults in the United States: 2009 and 2010. J Dent Res 2012;91 914-920. 
4. Al-Zahrani MS, Bissada NF, Borawski EA. Poor overall diet quality as a potential risk factor for periodontitis. J Periodontol 2003;74:1402 (Abstr.).

5. Bernabé E, Marcenes W. Periodontal disease and quality of life in British adults. J Clin Periodontol 2010; 37:968-972.

6. Demmer RT, Jacobs DR Jr., Desvarieux M. Periodontal disease and incident type 2 diabetes: Results from the First National Health and Nutrition Examination Survey and its epidemiologic follow-up study. Diabetes Care 2008;31:1373-1379.

7. $\mathrm{Xu} \mathrm{F}$, Lu B. Prospective association of periodontal disease with cardiovascular and all-cause mortality: NHANES III follow-up study. Atherosclerosis 2011;218: 536-542.

8. Genco RJ, Borgnakke WS. Risk factors for periodontal disease. Periodontol 2000 2013;62:59-94.

9. Grundy SM, Cleeman JI, Daniels SR, et al; American Heart Association; National Heart, Lung, and Blood Institute. Diagnosis and management of the metabolic syndrome: An American Heart Association/National Heart, Lung, and Blood Institute Scientific Statement. Circulation 2005; 112:2735-2752.

10. Wilson PW, D'Agostino RB, Parise H, Sullivan L, Meigs JB. Metabolic syndrome as a precursor of cardiovascular disease and type 2 diabetes mellitus. Circulation 2005; 112:3066-3072.

11. Ford ES, Li C, Zhao G. Prevalence and correlates of metabolic syndrome based on a harmonious definition among adults in the US. J Diabetes 2010;2:180-193.

12. Carr MC. The emergence of the metabolic syndrome with menopause. J Clin Endocrinol Metab 2003;88: 2404-2411.

13. Southerland JH, Taylor GW, Moss K, Beck JD, Offenbacher S. Commonality in chronic inflammatory diseases: Periodontitis, diabetes, and coronary artery disease. Periodontol 2000 2006;40:130-143.

14. Benguigui C, Bongard V, Ruidavets JB, et al. Metabolic syndrome, insulin resistance, and periodontitis: A cross-sectional study in a middle-aged French population. J Clin Periodontol 2010;37:601-608.

15. D'Aiuto F, Sabbah W, Netuveli G, et al. Association of the metabolic syndrome with severe periodontitis in a large U.S. population-based survey. JClin Endocrinol Metab 2008;93:3989-3994.

16. Fukui N, Shimazaki Y, Shinagawa T, Yamashita Y. Periodontal status and metabolic syndrome in middleaged Japanese. J Periodontol 2012;83:1363-1371.

17. Han DH, Lim S, Paek D, Kim HD. Periodontitis could be related factors on metabolic syndrome among Koreans: A case-control study. J Clin Periodontol 2012;39:30-37.

18. Han DH, Lim SY, Sun BC, Paek D, Kim HD. The association of metabolic syndrome with periodontal disease is confounded by age and smoking in a Korean population: The Shiwha-Banwol Environmental Health Study. J Clin Periodontol 2010;37:609-616.

19. Kushiyama M, Shimazaki Y, Yamashita Y. Relationship between metabolic syndrome and periodontal disease in Japanese adults. J Periodontol 2009;80:1610-1615.

20. Li P, He L, Sha YQ, Luan QX. Relationship of metabolic syndrome to chronic periodontitis. J Periodontol 2009; 80:541-549.

21. Morita T, Ogawa Y, Takada K, et al. Association between periodontal disease and metabolic syndrome. J Public Health Dent 2009;69:248-253.

22. Nesbitt MJ, Reynolds MA, Shiau H, Choe K, Simonsick EM, Ferrucci L. Association of periodontitis and metabolic syndrome in the Baltimore Longitudinal Study of Aging. Aging Clin Exp Res 2010;22:238-242.

23. Shimazaki Y, Saito T, Yonemoto K, Kiyohara Y, Iida M, Yamashita Y. Relationship of metabolic syndrome to periodontal disease in Japanese women: The $\mathrm{Hi}$ sayama Study. J Dent Res 2007;86:271-275.

24. Timonen $P$, Niskanen M, Suominen-Taipale L, Jula A, Knuuttila M, Ylöstalo P. Metabolic syndrome, periodontal infection, and dental caries. J Dent Res 2010; 89:1068-1073.

25. LaMonte MJ, Hovey KM, Genco RJ, Millen AE, Trevisan $M$, Wactawski-Wende J. Five-year changes in periodontal disease measures among postmenopausal females: The Buffalo OsteoPerio study. J Periodontol 2013;84:572-584.

26. Millen AE, Hovey KM, LaMonte MJ, et al. Plasma 25-hydroxyvitamin D concentrations and periodontal disease in postmenopausal women. J Periodontol 2013; 84:1243-1256.

27. Wactawski-Wende J, Hausmann E, Hovey K, Trevisan M, Grossi S, Genco RJ. The association between osteoporosis and alveolar crestal height in postmenopausal women. J Periodontol 2005;76(Suppl. 11):2116-2124.

28. Langer RD, White E, Lewis CE, Kotchen JM, Hendrix SL, Trevisan M. The Women's Health Initiative Observational Study: Baseline characteristics of participants and reliability of baseline measures. Ann Epidemiol 2003;13(Suppl. 9):S107-S121.

29. National Institute of Dental Research. Diagnostic criteria for dental examinations. In: Oral Health of United States Adults. Epidemiology and Oral Disease Prevention Program. Bethesda, MD: National Institutes of Health; 1987:1-115. NIH publication no. 87-2868.

30. Gibbs CH, Hirschfeld JW, Lee JG, et al. Description and clinical evaluation of a new computerized periodontal probe - The Florida probe. J Clin Periodontol 1988;15: 137-144.

31. Hausmann E, Allen K, Dunford R, Christersson L. A reliable computerized method to determine the level of the radiographic alveolar crest. $J$ Periodontal Res 1989;24:368-369.

32. Page RC, Eke PI. Case definitions for use in populationbased surveillance of periodontitis. J Periodontol 2007; 78(Suppl. 7):1387-1399.

33. Pearson TA, Mensah GA, Alexander RW, et al; Centers for Disease Control and Prevention; American Heart Association. Markers of inflammation and cardiovascular disease: Application to clinical and public health practice: A statement for healthcare professionals from the Centers for Disease Control and Prevention and the American Heart Association. Circulation 2003;107: 499-511.

34. Hanley AJ, Wagenknecht LE, D'Agostino RB Jr., Zinman B, Haffner SM. Identification of subjects with insulin resistance and beta-cell dysfunction using alternative definitions of the metabolic syndrome. Diabetes 2003;52:2740-2747.

35. Meigs JB, Rutter MK, Sullivan LM, Fox CS, D'Agostino RB Sr., Wilson PW. Impact of insulin resistance on risk of type 2 diabetes and cardiovascular disease in people with metabolic syndrome. Diabetes Care 2007;30: 1219-1225.

36. Matthews DR, Hosker JP, Rudenski AS, Naylor BA, Treacher DF, Turner RC. Homeostasis model assessment: Insulin resistance and beta-cell function from fasting plasma glucose and insulin concentrations in man. Diabetologia 1985;28:412-419. 
37. Genco RJ. Host responses in periodontal diseases: Current concepts. J Periodontol 1992;63(Suppl. 4): 338-355.

38. Vincent GK, Velkoff VA. The next four decades: The older population in the United States: 2010 to 2050. Current Population Reports, P25-1138, Washington, DC: U.S. Census Bureau, 2010:1-14.

39. Gorman A, Kaye EK, Apovian C, Fung TT, Nunn M, Garcia RI. Overweight and obesity predict time to periodontal disease progression in men. J Clin Periodontol 2012;39:107-114.

40. Chacko SA, Song Y, Manson JE, et al. Serum 25hydroxyvitamin $D$ concentrations in relation to cardiometabolic risk factors and metabolic syndrome in postmenopausal women. Am J Clin Nutr 2011;94: 209-217.

41. Neuhouser ML, Howard B, Lu J, et al. A low-fat dietary pattern and risk of metabolic syndrome in postmenopausal women: The Women's Health Initiative. Metabolism 2012;61:1572-1581.

Correspondence: Dr. Michael J. LaMonte, Department of Epidemiology and Environmental Health, 270 Farber Hall, University at Buffalo, 3435 Main Street, Buffalo, NY 14214. Fax: 716/829-2979; e-mail: mlamonte@buffalo.edu.

Submitted March 26, 2014; accepted for publication April 30, 2014. 